RESEARCH ARTICLE

\title{
Repairing Trust Between Individuals and Groups: The Effectiveness of Apologies in Interpersonal and Intergroup Contexts
}

\author{
Christopher P. Reinders Folmer*, Tim Wildschut ${ }^{\dagger}$, Tessa Haesevoets ${ }^{\ddagger}$, Jonas De \\ keersmaecker ${ }^{\S}$, Jasper Van Assche ${ }^{\ddagger}$ and Paul A. M. Van Langell
}

\begin{abstract}
Transgressions and injustice are an inevitable part of social life, both in interactions between individuals and between groups. But whereas conflict between individuals typically impacts only few, conflict between groups can be harmful to many - as is illustrated by disputes between nations, political parties, and social groups. For this reason, it is crucial to understand how such transgressions can be restored. In interpersonal contexts, there is considerable evidence that apologies can restore transgressions and enable victims and perpetrators to reconcile. It is unknown, however, to what extent their remedial effectiveness may translate to conflicts between groups. The present research illuminates this question. In an experimental study $(N=272)$, we compared the effectiveness of apologies for restoring trust after transgressions between individuals or groups. Results revealed that both in interpersonal and intergroup contexts, apologies significantly increased trust. However, their impact was greater in interpersonal interactions (where they fully restored trust to its pre-transgression level) than in intergroup interactions (where they failed to fully restore trust). Furthermore, the effectiveness of apologies was shaped by their emotional content. In disputes between individuals, only apologies with secondary emotions fully restored trust. Conversely, in disputes between groups, neither apologies with primary emotions nor those with secondary emotions fully restored trust. This was explained by greater skepticism of apologies in intergroup contexts, particularly of apologies with secondary emotions. These findings underline that intergroup interactions are more competitive and distrusting than interpersonal interactions, and suggest that more extensive remedies may be required to reduce intergroup tensions.
\end{abstract}

Keywords: apology; trust; reconciliation; forgiveness; intergroup relations; interpersonal relations

In order for communities to thrive, it is essential that groups cooperate - from relations between social groups in society to coalitions between political parties, to interactions between country representatives on the world stage. In these and many other cases, the common good requires that groups forego their immediate self-interest, to enable better outcomes for the collective. Regrettably, however, examples abound where groups fail to do so. Groups often are tempted to place their immediate self-interest first; indeed, they may be more inclined to do so than individuals (Insko \& Schopler, 1998; Wildschut et al., 2003). Doing so may harm the welfare of the collective, relationships with other groups - even their own long-term outcomes,

\footnotetext{
* University of Amsterdam, NL

+ University of Southampton, GB

* Ghent University, BE

$\S$ Universitat Ramon Llull, Esade Business School, ES

" VU University Amsterdam, NL

Corresponding author: Christopher P. Reinders Folmer

(c.p.reindersfolmer@uva.nl)
}

which are typically better served by mutual cooperation. Critically, in interactions between groups, these consequences are harmful to many, as is illustrated by disputes between nations, political parties, and social groups. For this reason, it is essential to know how trust and cooperation between groups can be restored after such violations.

A considerable body of research demonstrates that in interpersonal relations, apologies are an effective means of restoring trust violations (for a meta-analysis, see Fehr, Gelfand, \& Nag, 2010). By apologizing for their transgressions, individuals can distance themselves from their actions, reaffirm the norms that were broken, and humble themselves before the victim, thereby enabling them to reconcile (Tavuchis, 1991). But does the remedial potential of apologies also apply to disputes between groups? This question is not well understood. It is true that in disputes between groups, victims frequently demand apologies from groups that wronged them. However, whether apologies are as effective in intergroup contexts as in interpersonal contexts is not yet clear. To begin with, groups often fail to provide apologies for their transgressions 
(Hornsey \& Wohl, 2013; Shnabel \& Nadler, 2015). When groups do apologize, their apologies are often indirect, made by leaders or representatives on behalf of the group as a whole (Philpot \& Hornsey, 2008). Furthermore, in context of historical wrongdoings, victim groups tend to respond skeptically to apologies from perpetrator groups (for a review, see Hornsey \& Wohl, 2013). Taken together, it is not clear whether the remedial potential of apologies in interpersonal contexts translates to intergroup relations.

The present research illuminates this question. In an experimental study, we compared the effectiveness of apologies for restoring trust between individuals with that for restoring trust between groups. In addition, we investigated if (and how) the remedial effectiveness of apologies in these contexts depends on whether they are expressed in terms of primary (e.g., sadness and anger) or secondary (e.g., guilt and disappointment) emotions.

\section{Interpersonal versus Intergroup Interactions}

A rich history of research explores the psychological differences between intergroup and interpersonal interactions (for a review, see Wildschut et al., 2003). This literature reveals that psychological processes that result from (a) interacting within a group and (b) interacting against a group combine to make intergroup interactions more competitive than interpersonal interactions (Insko \& Schopler, 1998; Wildschut, Insko, \& Pinter, 2007). First, in intergroup interactions, group members often develop norms to favor their group over others (Pinter et al., 2007; Wildschut \& Insko, 2006), and provide each other with social support to do so (Wildschut, Insko, \& Gaertner, 2002). These processes are fueled by the notion that, as group members, they are less identifiable and accountable than they are in interpersonal interactions (Schopler et al., 1995; Wildschut \& Insko, 2007). Accordingly, when they act as part of a group, people develop more self-regarding and competitive motives than when they act as isolated individuals (i.e., greed; Reinders Folmer et al., 2012). Second, in intergroup interactions, group members interact with outgroups, rather than other individuals. Research has demonstrated that people tend to be fearful of the intentions of outgroups, and expect them be untrustworthy and competitive (i.e., schema-based distrust; Wildschut, Insko, \& Pinter, 2004). High levels of distrust are also characteristic of situations where people interact as representatives of two groups, rather than as two individuals (i.e., fear; Reinders Folmer et al., 2012). Taken together, relative to interpersonal interactions, intergroup interactions evoke a more competitive mindset, which promotes harmful noncooperation and conflict.

Nevertheless, research also demonstrates that groups have the capacity to cooperate effectively. For example, intergroup interactions produce levels of cooperation that are no lower than interpersonal interactions when the groups are represented by high guilt-prone leaders who cannot be directly held accountable by their constituencies (Pinter et al., 2007). Similarly, groups achieve high levels of cooperation when their interests are less incompatible (Schopler et al., 2001), when they can gradually build cooperation (Reinders Folmer et al., 2019), and when they anticipate interacting with each other in the future
(Insko et al., 2001). However, an important reason why this potential is often not reached is that, in intergroup interactions, people are less inclined to resume cooperation when others (perhaps unintentionally) violate their trust (Reinders Folmer et al., 2019). As such, rebuilding trust in the wake of such transgressions is vital for securing intergroup cooperation.

\section{Apologies as a Means for Restoring Trust and Cooperation}

The psychological literature lacks consensus on what an apology constitutes, and studies therefore have employed a broad range of operationalizations (for an overview, see Slocum, Allan, \& Allan, 2011). Broadly, an apology may be defined as 'an explicit verbal or written statement of one's regret, remorse, or sorrow for having insulted, failed, injured, or wronged another' (Tavuchis, 1991). Although apologies may incorporate additional elements (Dhami, 2012; Schumann, 2014), admission of wrongdoing and expression of regret and sorrow are the core components in most conceptualizations of apology (Slocum et al., 2011).

Apologies are an effective means of rebuilding damaged interpersonal relationships (Fehr et al., 2010). They can help to restore relations following transgressions because of several, interrelated functions. By apologizing for their actions, perpetrators distance themselves from their transgressions. By doing so, they acknowledge the wrongfulness of their behavior, and reaffirm the norms that they violated (Okimoto \& Tyler, 2007; Shnabel \& Nadler, 2015). Perpetrators thereby symbolically humble themselves and submit themselves to the victim's power to forgive (Tavuchis, 1991). Through these processes, an effective apology serves to reconfirm the norms that have been broken and rebuild the damaged status of the offender, thereby reestablishing trust and willingness to reinstate cooperation.

But does the effectiveness of apologies also translate to intergroup interactions? In functional terms, it seems plausible that it would. Research on intergroup conflict indicates that groups strongly desire for outgroups to recognize their wrongs and to apologize for them (Hornsey, Okimoto, \& Wenzel, 2017). Yet, apologies may be less effective as a remedial tool after intergroup transgressions. To begin with, in real-life intergroup conflicts, groups often fail to provide apologies (Hornsey \& Wohl, 2013). Rather than apologizing, perpetrator groups often seek to avoid unpleasant emotions like collective guilt, and therefore minimize their responsibility and the harm to victims (Shnabel \& Nadler, 2015). But even when groups do apologize, their apologies could be less persuasive than those between individuals. To begin with, group apologies are often made on behalf of the group by a leader or representative. In many situations, this means that the apology is delivered by someone who may not be directly responsible for the offense (Wenzel et al., 2018). This distinction may also mean that intergroup apologies are more formal, and more limited in emotional expression than interpersonal apologies (Philpot \& Hornsey, 2008; Tavuchis, 1991).

A second reason why apologies may be less effective in intergroup interactions is that groups may regard 
apologies as less convincing than individuals do. This possibility is suggested by research that focuses on apologies for historical wrongdoing and international disputes (for a review, see Hornsey \& Wohl, 2013). In such situations, apologies can be successful in increasing impressions of remorse, but often fail to promote forgiveness (Philpot \& Hornsey, 2008). A reason for this is that in such situations, groups are skeptical of apologies, in terms of the motives that prompt them (e.g., ulterior motives, like avoiding punishment); in terms of the sentiments that they convey (e.g., insincerity of remorse); and in terms of the extent to which they predict systemic change in the outgroup's behavior (e.g., cheap talk; Hornsey \& Wohl, 2013). These naturalistic findings are in line with laboratory research showing that, relative to interpersonal interactions, interactions between groups are characterized by greater fear and distrust (Insko \& Schopler, 1998; Wildschut et al., 2003), and by more competitive expectations (Pemberton, Insko, \& Schopler, 1996; Reinders Folmer et al., 2012).

A third reason that apologies may be less persuasive in intergroup contexts relates to their emotional content. As noted, emotions such as regret, guilt, remorse, or sorrow are an integral part of apology (Slocum et al., 2011; Tavuchis, 1991). They contribute to their effectiveness by signaling the offender's internal state of contrition, their recognition that they violated norms, and their intention to refrain from this in the future (Hareli \& Eisikovits, 2006). However, research on infrahumanization suggests that people regard outgroups as less capable of experiencing such emotions (Leyens et al., 2000; Haslam \& Loughnan, 2014). More specifically, this perspective assumes that people discriminate between basic, primary emotions (e.g., fear, anger, sadness, pleasure), and higher-order, secondary emotions (e.g., shame, sorrow, guilt, disappointment). Whereas primary emotions are basic and shared by both humans and animals, secondary emotions are more advanced and uniquely human. Crucially, infrahumanization research demonstrates that people regard outgroups as less human than ingroups, and hence, less capable of experiencing complex emotions (Leyens et al., 2000; Haslam \& Loughnan, 2014). Thus, the emotional content that is conveyed by apologies may seem less credible when expressed by outgroups. In line with this idea, Wohl, Hornsey, and Bennett (2012) demonstrated that, in context of a real-life international dispute, ingroup members showed less forgiveness when the outgroup expressed secondary emotions in their apology.

Taken together, we hypothesize that apologies restore trust less effectively in intergroup interactions than in interpersonal interactions. We further propose that, in intergroup (compared to interpersonal) interactions, people will regard apologies as less sincere, and as a result, will be less inclined to reinstate trust and cooperation after an apology. Moreover, research on infrahumanization suggests that these processes may be contingent on the emotional content of the apology, such that the effectiveness of apologies in intergroup contexts may especially be reduced when they convey secondary emotions (e.g., guilt, disappointment).

\section{The Present Research}

Apologies are an effective means of restoring trust in interpersonal interactions, but it is unclear whether this extends to intergroup interactions. The literature on intergroup apology, which focuses especially on historical and international wrongdoing, suggests that apologies may be ineffective in intergroup interactions (Hornsey \& Wohl, 2013). The literature on infrahumanization suggests that especially the emotional content of apologies may undermine their effectiveness in disputes between groups (Wohl et al., 2012). However, to our knowledge, no study has directly compared these processes in interactions between individuals or groups, or in contexts that do not involve historical wrongdoing or international disputes.

We examined these processes in an experiment, situated in an actual intergroup context, namely that between the Dutch-speaking and French-speaking linguistic communities in Belgium (i.e., Flanders and Wallonia). Although they are part of the same country, these communities are characterized by relatively distinct identities, and are situated in different regions separated by a permanent linguistic border. Both regions have their own government and institutions, under a federal umbrella. The communities share a long-standing history since the country's establishment in 1831, which has been characterized by occasional tension over language, socio-economic imbalances, and reforms of the state (for more information, see Reuchamps et al., 2021; Van Assche et al., 2017; Verhaegen et al., 2021). Nevertheless, in both communities, a majority has remained committed to a future under the collective Belgian state (see Billiet et al., 2006; De Visscher \& Laborderie, 2013; Rimé et al., 2015). These features make these communities ideally suited as meaningful outgroups.

In our experiment, Flemish participants either interacted individually with another individual (with no salient community identities), or as part of a group of Flemish participants who interacted with a group of Walloons. In both contexts, participants were confronted with a trust violation. After this transgression, they either did or did not receive an apology, the emotional content of which we varied. We examined how apologies impacted the restoration of trust in interpersonal and intergroup interactions, in terms of self-reported trust (measured at three time points), perceived sincerity, and trusting behavior.

\section{Method \\ Participants}

Participants were 279 secondary school students (183 women, 95 men, 1 unregistered) from the same grade in two Flemish schools (130 general secondary education, 148 technical secondary education, 1 unregistered). They were aged between 16 and 19 years (Mage $=16.98$, SDage $=0.70$ ). They were assigned to conditions in a 2 (interaction type: interpersonal vs. intergroup) $\times 3$ (apology type: no apology, apology with primary emotions, apology with secondary emotions) $\times 3$ (measurement time: before transgression, after transgression, after response) design, with the latter being a within-participant variable. A power analysis with $G^{*}$ Power (Faul, Erdfelder, Lang, \& Buchner, 
2007) indicated that this sample was sufficiently powered to detect (within-between) interactions at $f=0.25$.

\section{Procedure}

We administered the experiment as a paper-and-pencil task and conducted it in class. The experimenter read out the instructions on every page, after which the participants completed the questions, either individually or after discussion in groups. We debriefed participants after completing data collection.

\section{Manipulation of interaction type}

The experimenter informed participants that two individuals (in the interpersonal condition) or two groups (in the intergroup condition) interacted with each other. The experimenter explained that the study employed a lagged design, such that participants were paired with other participants, who had previously taken part in the study. In fact, these other participants were simulated, and their responses were designed by the researchers. In the interpersonal condition, the task was described as an interaction between two students (i.e., individuals). Participants completed all materials individually. The materials referred to the interaction partner as another student, who had participated previously at a different location in Belgium. In the intergroup condition, the task was described as an interaction between a group of Flemish students (i.e., the participant's group) and a group of Walloon students. Participants were classified into groups of three participants. They were encouraged to discuss the task together; however, they subsequently completed the materials individually.

The experimental task was based on the Dictator game, with participants in the role of recipient. They learned that the study would examine how Belgian students (in the interpersonal condition) or Flemish and Walloon students (in the intergroup condition) divide money between each other, and they would respond to such divisions. To this end, one student [group of students] would receive an endowment of 1,000 euro, which they could divide between the two students [two groups of students]. The experimenter explained that money within this task did not represent actual money but could be traded for tickets in a raffle for cinema tickets. As such, earning money in the task would increase their chances of winning a prize. Participants learned that the study would include further tasks later on.

Participants learned that the student [group of students] with whom they were paired had participated earlier at a different location in Belgium [in Wallonia]. The experimenter told participants that because their interaction partner(s) had participated first, they had been the first to take from the shared endowment of 1,000 euro. Ostensibly, they had been allowed to take any amount, but had to leave at least 100 euro for the other participant [Flemish group]. Thus, this task represents a Dictator game, with the participant(s) in the role of Recipient, and the interaction partner(s) in the role of Allocator.

A separate form displayed the decision of the other student [Walloon group]. It indicated (in handwriting) that of the 1000 euro, the other student [Walloon group] had taken 900 euro for themselves and had left 100 euro for the participant [Flemish group]. Given that there were no clear reasons why one party should deserve so much more of the shared endowment, this division constitutes a breach of distributive rules and norms, and thus a transgression (Lerner, 1991; Wenzel, 2004).

\section{Manipulation of apology type}

After the division of the money was revealed, the manipulation of apology type was introduced. Participants learned that, after making their decision, the other student [Walloon group] had been asked to reflect on the consequences for the other student [Flemish group]. The other student [Walloon group] had then been given the option to apologize. Their response was displayed on a separate form. On this form, two checkboxes were displayed: "I [we] do not want to apologize" and "I [we] want to apologize". For participants in the no-apology condition, the first option was marked, and no other information was provided. For participants in the apology conditions, the second option was marked, and a (hand-written) apology was provided in a text field below. For participants in the intergroup interaction condition, the hand-written apology was in French, with a translation in Dutch below (ostensibly provided by the experimenter).

In the apology-with-primary-emotions condition, the message read: (I [we] want to apologize because): 'when I [we] think about the decision, I [we] feel sad and angry with myself [ourselves].' This apology refers to sadness and anger, two primary emotions. In the apology-withsecondary-emotions condition, the message read: (I [we] want to apologize because): "when I [we] think about the decision, I [we] feel guilty and am [are] disappointed with myself [ourselves].' Therefore, this apology refers to guilt and disappointment, two secondary emotions.

\section{Dependent Measures}

\section{Manipulation check}

To assess whether participants experienced the division as a transgression, they indicated whether they were satisfied with the division (Yes or No). We omitted six participants who did not experience the division as a transgression from the final analyses.

\section{Self-reported trust}

Self-reported trust was measured at three time points: (1) at the onset of the interaction, when participants had just been paired with the other student or Walloon group, (2) following the transgression, and (3) following the manipulation of apology type. We assessed trust with eight items, based on the measure of Desmet, De Cremer, and Van Dijk (2011): 'I trust the other [Walloon group],' 'The other is someone [Walloon group consists of people who] would deceive me [us] if it would be advantageous to him/her [them],' 'The other is someone [Walloon group consists of people who] would lie to me [us] if it would benefit him/ her [them],' 'I think the other [Walloon group] is trustworthy,' 'The other [Walloon group] means well with me [us],' 'I have no trust in the other [Walloon group],' 'The other [Walloon group] is honest,' and 'I can rely on the other [Walloon group]' (1 = completely disagree, $5=$ completely 
agree; items 2-3, and 6 reverse coded). We combined responses into an index of self-reported trust ( $\alpha$ s at each time point $\geq 0.83$ ).

\section{Perceived sincerity}

After the apology type manipulation, we assessed - for participants in both apology conditions - perceptions of sincerity with nine items: 'the message is sincere,' 'the message is credible,' 'with this message, the other [Walloon group] tries to manipulate me,' 'with this message, the other [Walloon group] wants to apologize,' 'the other [Walloon group] speaks the truth in their message,' 'I think the other [Walloon group] has not been sincere about his/her [their] feelings,' 'I doubt that the other [Walloon group] truly feels like he/she says [they say],' 'with this message, the other [Walloon group] tries to deceive me,' 'the other [Walloon group] truly feels the way that he/she is [they are] saying' ( 1 = completely disagree, 5 = completely agree; items 3 and $6-8$ reverse coded). We combined responses into an index of perceived sincerity $(\alpha=0.92)$.

\section{Trusting behavior}

To assess trusting behavior, participants completed a second decision task with the same student [Walloon group] at the end of the study. In this task, they played the role of Allocator, and the other student [Walloon group] played the role of Recipient. The task was a Trust game (Berg, Dickhaut, \& McCabe, 1995), in which participants received 10 additional raffle tickets. Participants could choose to keep the 10 tickets, or to transfer any number of tickets to the other student [Walloon group]. Any tickets sent would be tripled by the experimenter and then could be divided by the other student [Walloon group] (who thus could exploit them). The number of tickets transferred (0-10) was our measure of trusting behavior. ${ }^{1}$

\section{Results}

Our two main objectives were (1) to test the remedial effectiveness of apology (versus no apology) in interpersonal and intergroup interactions, and (2) to examine the effectiveness of apologies containing primary or secondary emotions in either context. To this end, our analyses focused on the following contrasts: (1) a contrast comparing the no apology condition to both apology conditions (the apology contrast), and (2) contrasts comparing (i) the no apology condition to apologies with primary emotions, (ii) the no apology condition to apologies with secondary emotions, and (iii) apologies with primary emotions to apologies with secondary emotions (the content contrasts). Finally, to directly assess the restoration of trust, we computed (3) a contrast comparing trust levels after the participants received the other (individual or group's) response with trust levels before the transgression took place (the restoration contrast). In all analyses, we controlled for education track (general or technical).

\section{Self-Reported Trust}

To examine the trajectory of participants' self-reported trust, we conducted a 2 (interaction type) $\times 3$ (apology type) $\times 3$ (measurement time) mixed ANOVA, with repeated measures on the latter variable. We display the results for this analysis in Table $\mathbf{1}$.

\section{Trust trajectory}

Results revealed three significant within-participant effects involving measurement time, indicating differences in trust across the three time points (Table 1). First, there was a significant main effect of measurement time. The level of trust was highest before the transgression took place (T1, $M=2.70, S D=0.68)$, decreased following the transgression $(\mathrm{T} 2, M=1.59, S D=0.61)$, and then increased after participants received the other (individual or group's) response (T3, $M=2.01, S D=0.86)$. Pairwise comparisons (Bonferroni-corrected) indicated that levels of self-reported trust differed significantly between all three time points $(p s<0.001)$.

Second, there was a significant Measurement Time $x$ Interaction Type interaction, indicating that the trust trajectory differed between interpersonal and intergroup interactions. Although interpersonal and intergroup

Table 1: Effects of interaction type, apology type, and measurement time on self-reported trust.

\begin{tabular}{lrrrr} 
& \multicolumn{1}{c}{$\boldsymbol{F}$} & $\mathbf{d f}$ & $\boldsymbol{p}$ & $\boldsymbol{f}$ \\
\hline \multicolumn{1}{c}{ Within-participant effects } & & & \\
\hline Measurement time & 51.41 & $1.92,507.87$ & $<0.001$ & 0.44 \\
Measurement time $\times$ Education track & 2.30 & $1.92,507.87$ & 0.103 & 0.09 \\
Measurement time $\times$ Interaction type & 10.50 & $1.92,507.87$ & $<0.001$ & 0.20 \\
Measurement time $\times$ Apology type & 33.06 & $3.85,507.87$ & $<0.001$ & 0.50 \\
Measurement time $\times$ Interaction type $\times$ Apology type & 1.58 & $3.85,507.87$ & 0.181 & 0.11 \\
& Between-participant effects & & & \\
\hline Education track (covariate) & 8.42 & 1,264 & 0.004 & 0.18 \\
Interaction type & 8.95 & 1,264 & 0.003 & 0.18 \\
Apology type & 6.81 & 2,264 & $<0.001$ & 0.23 \\
Interaction type $\times$ Apology type & 4.55 & 2,264 & 0.011 & 0.18
\end{tabular}


interactions did not differ in trust before the transgression (T1, interpersonal: $M=2.69, S D=0.72$, intergroup: $M=$ $2.70, S D=0.65 ; F(1,264)=0.03, p=0.871, f=0.00)$, trust was significantly lower in intergroup interactions than in interpersonal interactions following the transgression (T2, interpersonal: $M=1.68, S D=0.66$, intergroup: $M=1.50$, $S D=0.54 ; F(1,264)=6.25, p=0.013, f=0.15)$ and after receiving the other (individual or group's) response (T3, interpersonal: $M=2.17, S D=0.90$, intergroup: $M=1.83$, $S D=0.77 ; F(1,264)=19.50, p<0.001, f=0.27)$.

Third, a significant Measurement Time $\times$ Apology Type interaction indicated that the trust trajectory depended on apology type. Because the apology type manipulation was introduced after the transgression (T2), it could not (and did not) affect trust at T1 or T2. Apology type did, however, affect trust at T3 (Table 2). The apology contrast indicated that participants reported significantly more trust at $\mathrm{T} 3$ when the other (individual or group) had apologized than when the other (individual or group) had not apologized (Table 2). The content contrasts indicated that both apologies with primary emotions and apologies with secondary emotions increased trust (compared to no apology, Table 3).

\section{Overall trust}

Results further revealed three significant between-participant effects on overall trust across time (Table 1). First, there was a significant main effect of interaction type, indicating that overall trust was greater in interpersonal interactions $(M=2.18, S D=0.59)$ than in intergroup interactions $(M=2.01, S D=0.54)$.

Second, the analysis revealed a significant main effect of apology type (attributable to T3, see above). A significant apology contrast indicated that participants who received an apology from the other (individual or group) reported more trust than participants who did not receive an apology (Table 2). The content contrasts indicated that both apologies with primary emotions and apologies with secondary emotions increased overall trust (compared to no apology, Table 3).

Third, results revealed a significant Interaction Type $\times$ Apology Type interaction effect. Apologies significantly increased overall trust (compared to no apology) in interpersonal interactions, but not in intergroup interactions (Table 2). The content contrasts indicated that, in interpersonal interactions, both apologies with primary emotions and apologies with secondary emotions increased overall trust (compared to no apology). Conversely, in intergroup interactions, only apologies with primary emotions increased overall trust (compared to no apology) (Table 3). Because the apology type interaction was implemented after T2, it could only affect trust at T3. For this reason, we next zoomed in on the Interaction Type $\times$ Apology Type interaction effect at T3, when participants had received the other (individual or group's) response. ${ }^{2}$

At T3, the apology contrast indicated that apologies increased trust in interpersonal interactions. In intergroup interactions, apologies also increased trust, but to a smaller extent than in interpersonal contexts (Table 2). The content contrasts showed that apologies with primary emotions and apologies with secondary emotions increased trust (compared to no apology) in both interpersonal and intergroup interactions (Table 3). However, both types of apology - and particularly apologies with secondary emotions - increased trust to a greater extent in interpersonal interactions than in intergroup interactions (Table 3). ${ }^{3}$

Finally, the analysis also revealed a significant effect of the education track covariate (Table 1), indicating that overall trust was higher among participants in general secondary education $(M=2.01, S D=0.86)$ than among participants in technical secondary education $(M=1.91$, $S D=0.82)$.

Trust restoration

Finally, we examined to what extent apologies effectively restored trust by comparing trust levels after the apology (T3) to trust levels before the transgression (T1, Figures 1a and 1b). For apologies with secondary emotions, the restoration contrast was not significant for interpersonal interactions, $F(1,264)=0.12, p=0.727, f=0.00$, indicating that these apologies restored trust between individuals to the level before the transgression. Conversely, the restoration contrast was significant in intergroup interactions, $F(1,264)=25.93, p<0.001 f=0.31$, indicating that trust

Table 2: Apology contrast for overall trust and trust after manipulation of response time (third time point).

\begin{tabular}{|c|c|c|c|c|c|c|}
\hline & \multicolumn{2}{|c|}{ Apology type } & \multirow{2}{*}{\multicolumn{4}{|c|}{$\begin{array}{c}\text { Univariate effects } \\
\text { No apology vs. Apology }\end{array}$}} \\
\hline & \multirow{2}{*}{$\begin{array}{c}\text { No apology } \\
M(S D)\end{array}$} & \multirow{2}{*}{$\begin{array}{c}\text { Apology } \\
M(S D)\end{array}$} & & & & \\
\hline & & & $F$ & df & $p$ & $f$ \\
\hline \multicolumn{7}{|c|}{ Overall trust } \\
\hline Interpersonal interaction & $1.96(0.54)$ & $2.29(0.59)$ & 11.85 & 1,264 & 0.001 & 0.21 \\
\hline Intergroup interaction & $1.91(0.52)$ & $2.05(0.55)$ & 1.78 & 1,264 & 0.183 & 0.08 \\
\hline Total & $1.94(0.53)$ & $2.17(0.57)$ & 10.94 & 1,264 & 0.001 & 0.20 \\
\hline \multicolumn{7}{|c|}{ Trust after manipulation (T3) } \\
\hline Interpersonal interaction & $1.49(0.56)$ & $2.53(0.84)$ & 62.15 & 1,264 & $<0.001$ & 0.53 \\
\hline Intergroup interaction & $1.41(0.61)$ & $2.01(0.76)$ & 17.88 & 1,264 & $<0.001$ & 0.26 \\
\hline Total & $1.45(0.58)$ & $2.26(0.84)$ & 71.63 & 1,264 & $<0.001$ & 0.58 \\
\hline
\end{tabular}


Table 3: Content contrasts for overall trust and trust after manipulation of response time (third time point).

\begin{tabular}{|c|c|c|c|c|c|c|c|c|c|c|c|c|}
\hline & \multicolumn{3}{|c|}{ Apology type } & \multicolumn{9}{|c|}{ Univariate effects } \\
\hline & \multirow{2}{*}{$\begin{array}{c}\text { No apology } \\
M(S D) \\
\end{array}$} & \multirow{2}{*}{$\begin{array}{l}\text { Primary } \\
M(S D) \\
\end{array}$} & \multirow{2}{*}{$\begin{array}{c}\text { Secondary } \\
M(S D)\end{array}$} & \multicolumn{3}{|c|}{$\begin{array}{c}\text { No apology vs. } \\
\text { Primary }\end{array}$} & \multicolumn{3}{|c|}{$\begin{array}{l}\text { No apology vs. } \\
\text { Secondary }\end{array}$} & \multicolumn{3}{|c|}{$\begin{array}{l}\text { Primary vs. } \\
\text { Secondary }\end{array}$} \\
\hline & & & & $F$ & $p$ & $f$ & $F$ & $p$ & $f$ & $F$ & $p$ & $f$ \\
\hline \multicolumn{13}{|c|}{ Overall trust } \\
\hline $\begin{array}{l}\text { Interpersonal } \\
\text { interaction }\end{array}$ & $1.96(0.54)$ & $2.25(0.60)$ & $2.34(0.57)$ & 6.64 & 0.011 & 0.16 & 11.23 & 0.001 & 0.21 & 0.52 & 0.473 & 0.04 \\
\hline $\begin{array}{l}\text { Intergroup } \\
\text { interaction }\end{array}$ & $1.91(0.52)$ & $2.23(0.57)$ & $1.88(0.46)$ & 6.96 & 0.009 & 0.16 & 0.09 & 0.770 & 0.02 & 9.45 & 0.002 & 0.19 \\
\hline Total & $1.94(0.53)$ & $2.24(0.58)$ & $2.11(0.56)$ & 13.59 & $<0.001$ & 0.23 & 3.83 & 0.037 & 0.13 & 2.71 & 0.101 & 0.10 \\
\hline \multicolumn{13}{|c|}{ After manipulation (T3) } \\
\hline $\begin{array}{l}\text { Interpersonal } \\
\text { interaction }\end{array}$ & $1.49(0.56)$ & $2.39(0.88)$ & $2.66(0.80)$ & 34.56 & $<0.001$ & 0.37 & 59.20 & $<0.001$ & 0.51 & 2.85 & 0.092 & 0.10 \\
\hline $\begin{array}{l}\text { Intergroup } \\
\text { interaction }\end{array}$ & $1.41(0.62)$ & $2.13(0.82)$ & $1.88(0.70)$ & 19.70 & $<0.001$ & 0.27 & 8.98 & 0.003 & 0.18 & 2.29 & 0.131 & 0.09 \\
\hline Total & $1.45(0.58)$ & $2.25(0.85)$ & $2.27(0.84)$ & 52.96 & $<0.001$ & 0.48 & 55.91 & $<0.001$ & 0.49 & 0.02 & 0.888 & 0.01 \\
\hline
\end{tabular}

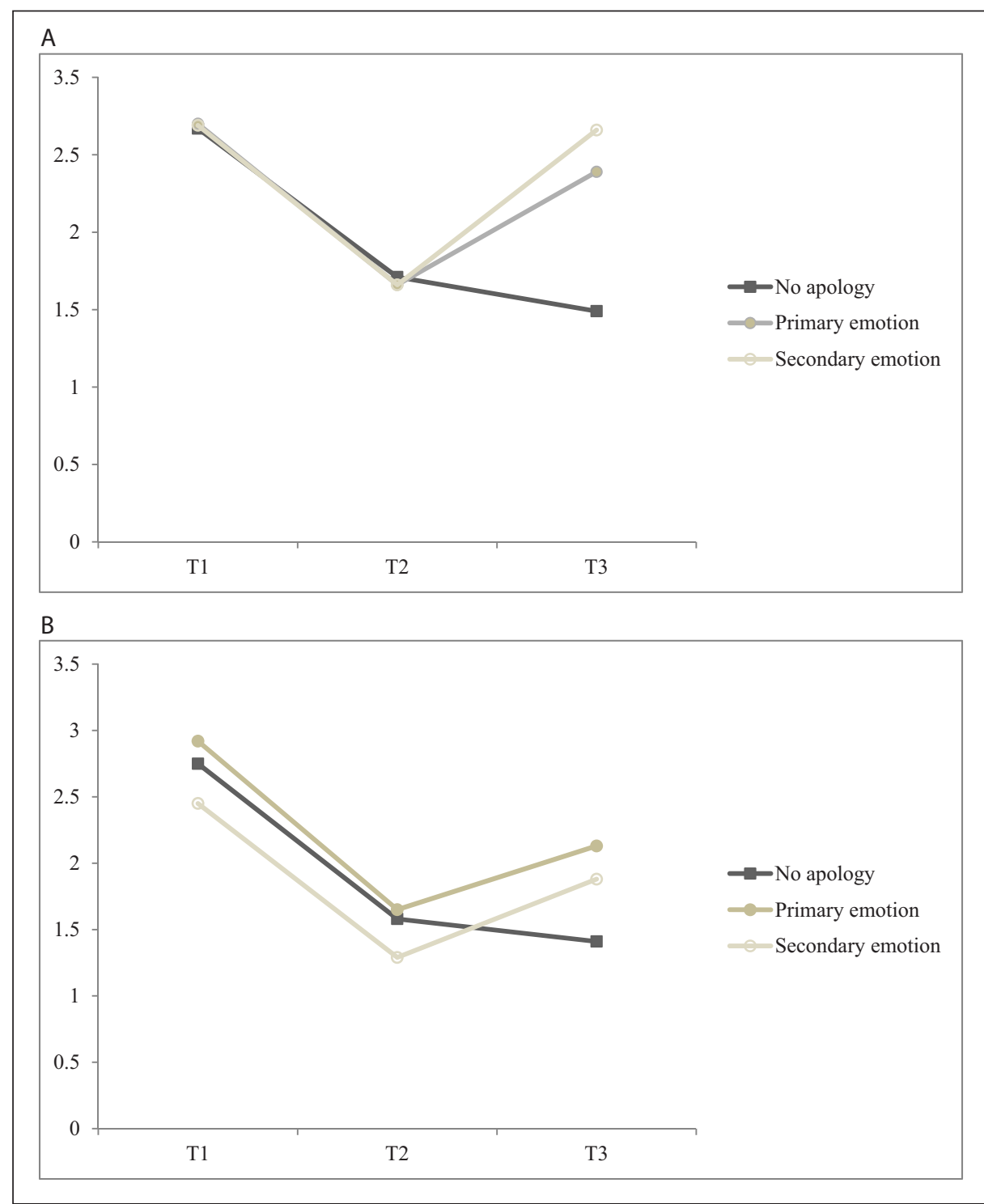

Figure 1: (a) Self-reported trust at T1, T2, and T3 by apology type in the interpersonal condition. (b) Self-reported trust at $\mathrm{T} 1, \mathrm{~T} 2$, and $\mathrm{T} 3$ by apology type in the intergroup condition. 
between groups was significantly lower after apologies with secondary emotions than before the transgression. For apologies with primary emotions, the restoration contrast was significant both for interpersonal interactions, $F(1,264)=7.24, p=0.008, f=0.17$, and for intergroup interactions, $F(1,264)=49.07, p<0.001, f=0.43$. Trust between both individuals and groups was lower after an apology with primary emotions than before the transgression.

\section{Perceived Sincerity}

Next, we examined perceptions of the sincerity of the apologies. Given that participants who received no apology did not complete these measures, this analysis only includes participants in the apology conditions. A 2 (interaction type) $\times 2$ (apology type) ANOVA revealed a significant main effect of interaction type, $F(1,181)=24.19, p<$ $0.001, f=0.37$. In interpersonal interactions, participants perceived apologies as more sincere $(M=2.87, S D=0.84)$ than in intergroup interactions $(M=2.32, S D=0.70)$. A trending Interaction Type $\times$ Apology Type interaction indicated that this difference between interpersonal and intergroup interactions varied as a function of apology type, $F(1,181)=3.46, p=0.064$. Specifically, apologies with secondary emotions were perceived as more sincere in interpersonal interactions $(M=2.98, S D=0.85)$ than in intergroup interactions $(M=2.21, S D=0.64), F(1,181)$ $=23.62, p<0.001, f=0.36$. Apologies with primary emo- tions were also perceived as more sincere in interpersonal interactions $(M=2.77, S D=0.83)$ than in intergroup interactions $(M=2.44, S D=0.75), F(1,181)=4.62, p=0.033$, $f=0.16$, but this difference was less pronounced than for apologies with secondary emotions.

\section{Trusting Behavior}

To examine participants' trusting behavior, we analyzed their contributions in the trust game in a 2 (interaction type) $\times 3$ (apology type) ANOVA (Table 4). Results revealed a significant main effect of interaction type, indicating that participants displayed less trusting behavior in intergroup interactions than in interpersonal interactions, $F(1,264)$ $=9.50, p=0.002, f=0.19$. The analysis further revealed a significant main effect of apology type, indicating that participants displayed more trusting behavior after an apology with primary emotions than after an apology with secondary emotions, or after no apology, $F(2,264)=$ $15.49, p<0.001, f=0.34$. The Interaction Type $\times$ Apology Type interaction was not significant, $F(2,264)=1.25, p=$ $0.288, f=0.09$.

\section{Mediation Analyses}

The results suggest that apologies evoked less trust, and lower perceived sincerity in intergroup interactions than in interpersonal interactions. We proposed that apologies evoke less trust in intergroup interactions than in interpersonal interactions because they are regarded as less

Table 4: Trusting behavior as a function of interaction type and apology type.

\begin{tabular}{lcccc} 
Interaction type & \multicolumn{4}{c}{ Apology type } \\
\cline { 2 - 5 } & No apology & Primary emotions & Secondary emotions & Total \\
\cline { 2 - 5 } & $\boldsymbol{M}(\boldsymbol{S D})$ & $\boldsymbol{M}(\boldsymbol{S D})$ & $\boldsymbol{M}(\boldsymbol{S D})$ & $\boldsymbol{M}(\boldsymbol{S D})$ \\
\hline Interpersonal & $1.87(2.43)$ & $3.43(2.54)$ & $3.55(2.65)$ & $2.94(2.63)$ \\
Intergroup & $1.18(1.97)$ & $3.15(1.49)$ & $2.21(1.79)$ & $2.24(1.91)$ \\
Total & $1.56(2.25)$ & $3.29(2.06)$ & $2.88(2.34)$ & $2.60(2.33)$
\end{tabular}

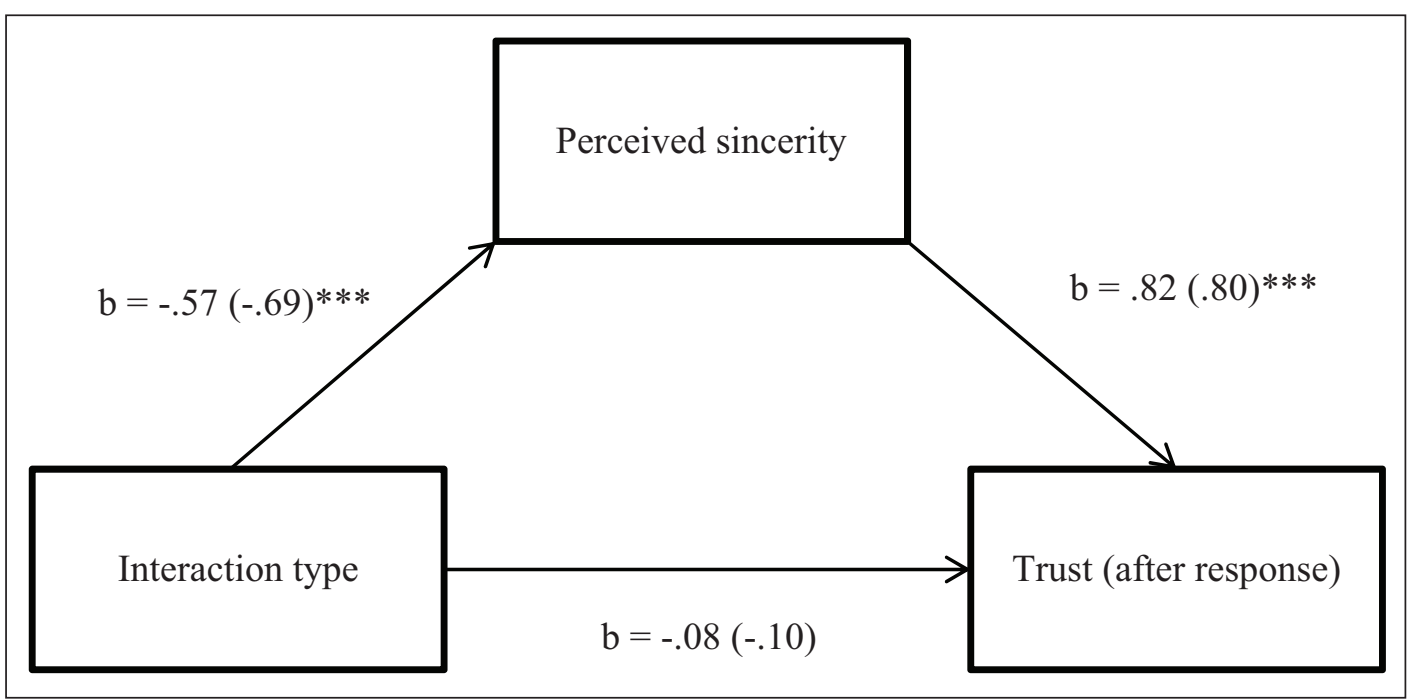

Figure 2: Indirect effect of interaction type on trust, mediated by perceived sincerity of apology. Note: ${ }^{*} p<0.05$, ${ }^{* *} p<0.01,{ }^{* * *} p<0.001$. 
sincere. To test this hypothesis, we conducted a mediation analysis by means of the PROCESS macro (Model 4, 5000 bootstrapped resamples; Hayes, 2013). In this analysis, interaction type was the predictor $(\mathrm{X})$, trust after the apology the dependent variable $(\mathrm{Y})$, and perceived sincerity of the apology the mediator $(\mathrm{M})$.

Unstandardized parameter estimates for the model are shown in Figure 2, with standardized estimates in parentheses. Interaction type had a significant negative effect on perceived sincerity; perceived sincerity was lower in intergroup interactions than in interpersonal interactions. Perceived sincerity, in turn, had a significant positive association with self-reported trust. The indirect effect $(a b)$ of interaction type on trust through perceived sincerity was significant, $a b=-0.47, S E=0.10,95 \% \mathrm{CI}$ $[-0.67,-0.28]$ (standardized: $a b=-0.55, S E=0.11,95 \%$ CI $[-0.77,-0.34])$. Thus, the lower perceived sincerity of apologies in intergroup interactions mediated the lower level of trust between groups (compared to individuals) after apologies.

Furthermore, we hypothesized that participants' lower trusting behavior in intergroup interactions (compared to interpersonal interactions) would be explained by their lower trust in this context, and that this would be moderated by the impact of apology. To test this hypothesis, we conducted a moderated mediation analysis by means of the PROCESS macro (Model 7, 5000 bootstrapped resamples; Hayes, 2013). In this analysis, interaction type was the predictor $(\mathrm{X})$, trusting behavior the dependent variable (Y), and trust after the response the mediator (M). Apology type was the moderator $(\mathrm{W})$.

Figure 3 presents the moderated mediation model; additionally, for ease of interpretation, Figure 4 presents the mediation model separately for each apologytype condition. In the moderated mediation model, the three-level apology-type variable was represented with two dummy variables. The first dummy variable compared the apology-with-primary-emotions condition to the no-apology condition (corresponding to the first content contrast). The second dummy variable compared the apology-with-secondary-emotions condition to the no-apology condition (corresponding to the second content contrast). The tendency for trust after the response to be lower in intergroup interactions than in interpersonal interactions was moderated by apology type. Specifically, a significant Interaction Type $\times$ Dummy 2 interaction indicated that this difference was larger in the apology-with-secondary-emotions condition than the no-apology condition, $b=-0.69, S E=0.22,95 \% \mathrm{CI}$ $[-1.12,-0.25]$. Conversely, relative to the no-apology condition, the difference in trust was not significantly larger in the apology-with-primary-emotions condition; Interaction Type $\times$ Dummy $1, b=-0.20, S E=0.22,95 \%$ CI $[-0.63,0.24]$. Trust, in turn, predicted more trusting behavior.

The analysis revealed a significant indirect effect of interaction type on trusting behavior, via trust, in the apology-with-secondary-emotions condition, $a b=$ $-0.78, S E=0.20,95 \%$ CI $[-1.20,-0.41]$ (Figure 4, panel C). Conversely, this indirect effect was not significant in the apology-with-primary-emotions condition, $a b=$ $-0.30, S E=0.18,95 \%$ CI $[-0.68,0.04]$ (panel B), or in the no-apology condition, $a b=-0.10, S E=0.12,95 \% \mathrm{CI}$ $[-0.33,0.16]$ (panel A). Last, we examined the indices of moderated mediation. For Dummy 2, the index of moderated mediation was negative and significant, index = $-0.68, S E=0.24,95 \% \mathrm{CI}[-1.22,-0.25]$. Thus, the indirect effect of interaction type on trusting behavior, via trust, was more negative in the apology-with-secondary-emotions condition than in the no-apology condition. Conversely, for Dummy 1, the index of moderated mediation was not significant, index $=-0.20, S E=0.22$,

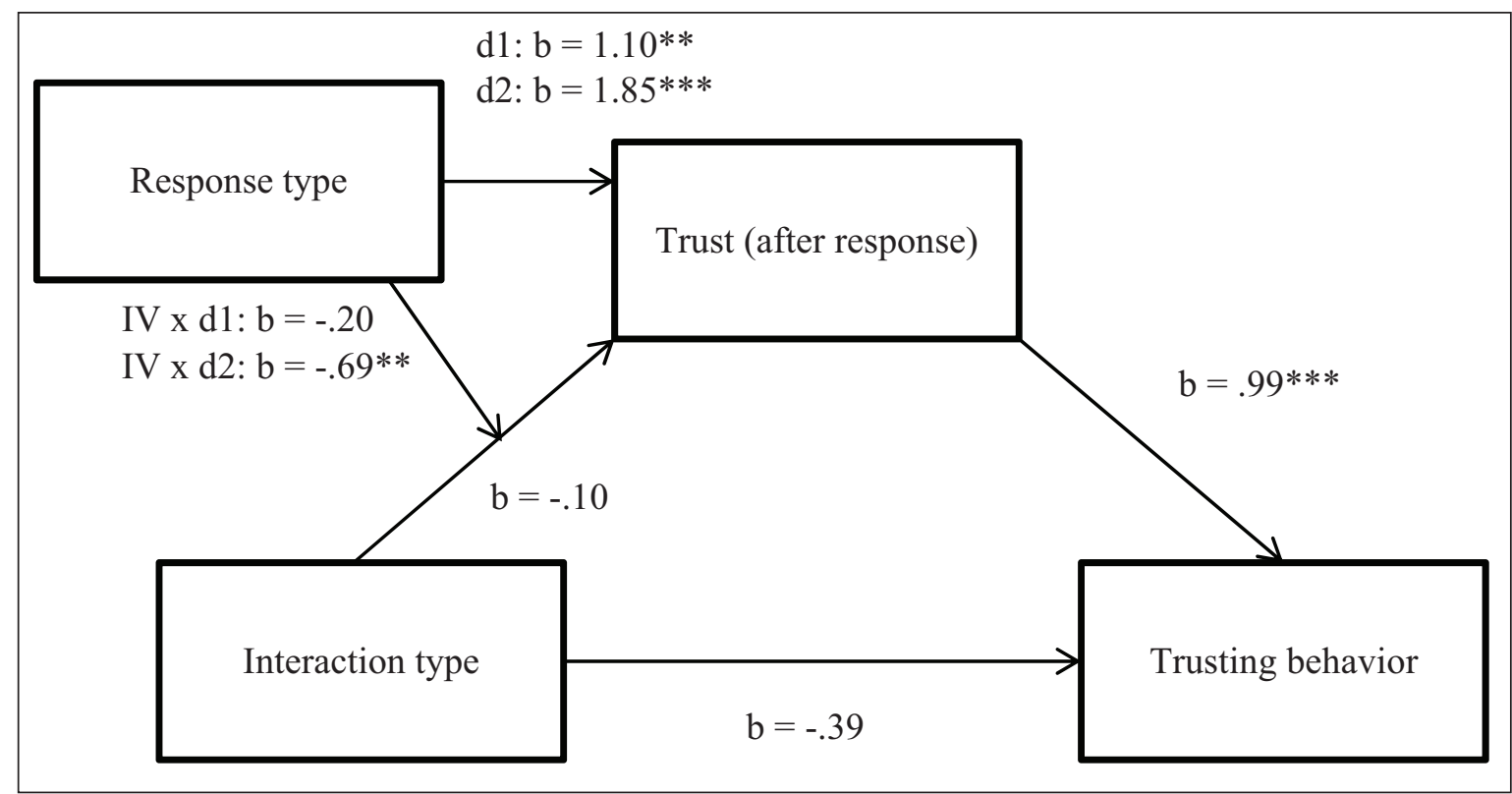

Figure 3: Indirect effect of interaction type on trusting behavior, mediated by trust and moderated by response type. Note: $\mathrm{d} 1$ = no response vs. apology with primary emotions; $\mathrm{d} 2=$ no response vs. apology with secondary emotions; * $=p<0.05,{ }^{* *}=p<0.01,{ }^{* * *}=p<0.001$. 
95\% CI $[-0.67,0.21]$. Hence, the indirect effect did not differ between the apology-with-primary-emotions condition and the no-apology condition. In sum, these results confirmed that the indirect effect of interaction type on trusting behavior, via trust, was moderated by apologies with secondary emotions (versus no apology), but not by apologies with primary emotions (versus no apology).

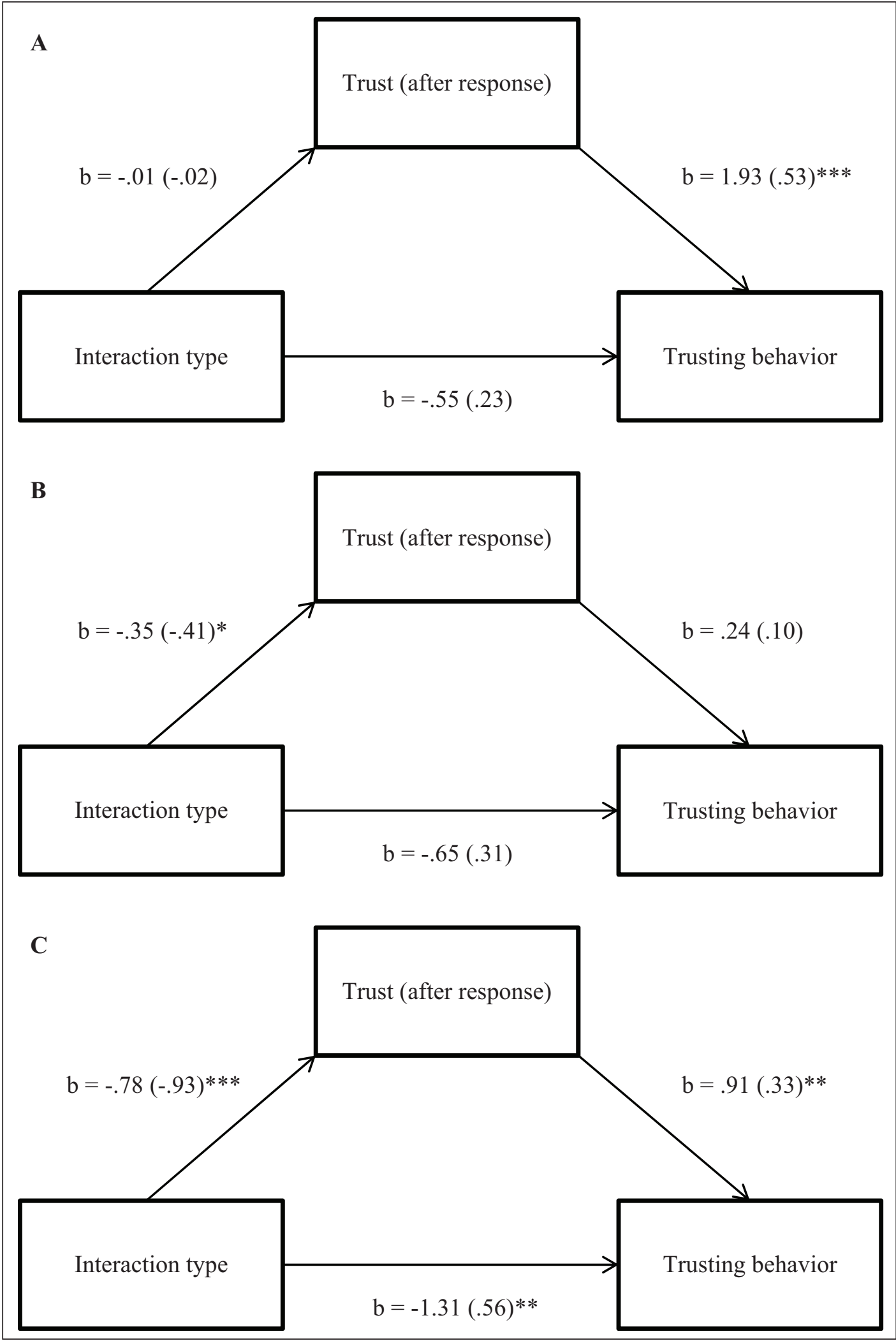

Figure 4: Indirect effect of interaction type on trusting behavior, mediated by trust; in the no apology condition (Panel A), apology-with-primary-emotions condition (Panel B), and apology-with-secondary-emotions condition (Panel C). Note: ${ }^{*} p<0.05,{ }^{* *} p<0.01,{ }^{* * *} p<0.001$. 


\section{Discussion}

The present research examined whether the remedial potential of apologies for resolving interpersonal conflicts translates to intergroup contexts. Our findings indicate that apologies restore trust less effectively in intergroup interactions than in interpersonal interactions. This was particularly true for apologies that conveyed secondary emotions (e.g., guilt and disappointment), which especially were experienced as less sincere in interactions between groups. This perceived lack of sincerity undermines the effectiveness of apologies for restoring psychological trust and trusting behavior in intergroup contexts. Nevertheless, although apologies were less effective in intergroup interactions than in interpersonal interactions, they did succeed in partially restoring trust between groups. Therefore, our findings indicate that apologies can play a remedial role in conflict between groups, in contrast to more pessimistic views (Philpot \& Hornsey, 2008; Hornsey \& Wohl, 2013).

\section{The Effectiveness of Apologies in Intergroup Interactions}

The notion that apologies were less effective in intergroup interactions is in line with the literature on the psychological differences between interpersonal and intergroup interactions (Insko \& Schopler, 1998; Wildschut et al., 2003). In particular, the notion that participants experienced apologies as less sincere in intergroup interactions aligns with findings that people have more competitive beliefs of other groups than of other individuals (Pemberton et al., 1996; Reinders Folmer et al., 2012). In intergroup contexts, people are less inclined to take conciliatory initiatives from outgroups at face value. This undermines the effectiveness of apologies relative to interpersonal contexts.

The finding that apologies were relatively less effective in intergroup interactions than in interpersonal interactions is also in line with evidence on apologies in intergroup disputes. In this literature, researchers have focused on the effectiveness of apologies for restoring historical transgressions and other severe wrongs between communities or nations (Hornsey \& Wohl, 2013). Yet, whereas some studies suggest that apologies are ineffective between groups (Philpot \& Hornsey, 2008; Wohl et al., 2012), the present findings reveal a picture that is more optimistic. Our findings indicate that for modest transgressions, framed in the intergroup context of the Belgian linguistic communities, apologies can help to increase trust between groups. These findings suggest, then, that the remedial potential of apology in intergroup contexts may be greater than previously thought. Nevertheless, further research is needed to evaluate this. Relative to the conflictual relationships on which prior research has focused (e.g., historical transgressions and other severe wrongs), the relationship between the Belgian linguistic communities features less animosity and resentment (e.g., see Van Assche et al., 2017). Nevertheless, this context may also differ from settings where groups have had only harmonious interaction histories, or no prior relationship. As such, further research is needed to understand how the interaction history between groups may affect the impact of an apology and its remedial effectiveness compared to interpersonal interactions. It seems plausible that apologies would become more effective to the extent that that groups had more cooperative interactions in the past, and less so the more that their prior interactions were characterized by conflict - although it should be noted that intergroup conflict may even arise between minimal groups with no prior interaction (e.g., Insko et al., 2001; Wildschut et al., 2007). It is also possible that apologies require a longer time frame to be effective in intergroup interactions. Groups may require a longer period of trustworthy behavior after an apology before they fully reinstate their trust. This is consistent with findings that groups can build up levels of cooperation that are similar to those among individuals in contexts where they can do so gradually (Reinders Folmer et al., 2019). As such, it is possible that even in the case of conflictual interaction histories, apologies still may constitute an important first step toward reconciliation between groups.

The effectiveness of apologies in intergroup interactions was contingent on their emotional content. Theorizing on apology holds that emotions like guilt are integral to an effective apology (Slocum et al., 2011; Tavuchis, 1991), and indeed, only apologies that featured these emotions fully restored trust between individuals. But, in intergroup interactions, secondary emotions evoked suspicion, and thereby undermined the remedial effect of apology on trust and trusting behavior. This finding suggests that the remedial value of apologies may remain more limited in intergroup contexts, because groups lack belief in the sincerity of its key elements when communicated by outgroups. Indeed, the literature on infrahumanization suggests that outgroups are seen as less capable of experiencing secondary emotions (Leyens et al., 2000; Haslam \& Loughnan, 2014). We suspect that deliberately withholding secondary emotions like remorse may be imprudent, in light of their central role in the process of reconciliation (Shnabel \& Nadler, 2015). In the present study, apologies with secondary emotions did increase trust between groups compared to no apology, despite circumstances that according to Hornsey and Wohl (2013) would constitute a low trust context (i.e., intentional transgression, high culpability, secondary emotions). Similarly, other studies also have demonstrated favorable effects of communicating higher-order emotions on intergroup trust (e.g., regret, Rychlowska et al., 2019; disappointment, Shore et al., 2019). These findings suggest that groups do not by definition respond neutrally or negatively to apologies with secondary emotions. Although groups may initially show greater skepticism toward such apologies, these may gain credibility in the longer run (e.g., by being substantiated by trustworthy behavior; see Wenzel et al., 2018) - and ultimately, may produce deeper reconciliation than is possible through apologies with (initially more credible, but less substantive) primary emotions.

\section{Limitations and Future Research}

In addition to the long-term effects of apology in interpersonal and intergroup contexts, future research should also further examine how differences in the effective- 
ness of apologies in either context may depend on their content. The present research focused on the emotions that apologies convey, which constitute some of their key elements (Slocum et al., 2011; Tavuchis, 1991). Nevertheless, the literature on apology distinguishes many other elements that may contribute to their effectiveness (e.g., explicit admission of responsibility; acknowledgement of victims' harm; Dhami, 2012; Schumann, 2014). It is possible that the apologies that people desire in intergroup interactions differ in comprehensiveness relative to interpersonal interactions. Furthermore, it may be that in intergroup interactions, people place greater value on tangible compensation than on apology (Haesevoets et al., 2013; Wenzel et al., 2018). By examining these processes, future research could illuminate how disputes between groups can best be restored - and how the recipe for doing so may differ from what is required in disputes between individuals.

If we are to unlock the remedial potential of apologies, it is crucial to understand not only how individuals and groups respond to such messages, but also when individuals and groups may provide them. Research on apology has focused mostly on the perspective of victims and victim groups (for a review, see Hornsey \& Wohl, 2013). Far less research has focused on perpetrators or perpetrator groups (Hornsey et al., 2017; Leunissen et al., 2013; Shnabel et al., 2009). Therefore, a crucial avenue for future research is to gain greater insight into the processes that lead people to apologize in interpersonal or intergroup contexts. By doing so, we may not only understand what tools can be effective for achieving reconciliation, but also how to enable their provision, so that their remedial potential can effectively be achieved - for groups and individuals.

\section{Concluding Remarks}

Following a transgression, apologies are an important instrument with which trust and cooperation can be restored in interpersonal interactions. But although transgressions are more likely to occur in intergroup interactions, apologies surprisingly have received relatively little empirical attention in this context. Understanding the workings of apology for mitigating intergroup conflict - their opportunities and limits - is also of considerable societal interest. Indeed, one only needs to watch headline news, or read a newspaper, to see examples of distrust, hostility, and even hate between groups. The scientific literature reveals that a competitive mindset can easily be triggered between groups, but uncovering ways to reduce or eliminate it is challenging (see Reinders Folmer et al., 2012). The present findings show that apologies can help to make a start at restoring trust, even in intergroup contexts. But it is only one piece of the puzzle. Unpacking the other pieces, such as how the perceived sincerity of apologies in intergroup contexts can be promoted, is a key scientific task for the future.

\section{Data Accessibility Statement}

All materials (data, scripts, and materials) are publicly available at https://osf.io/6myg8/.

\section{Notes}

${ }^{1}$ In addition, our study included measures of relationship preservation (Haesevoets, Reinders Folmer, De Cremer, \& Van Hiel, 2013), or participants' reported willingness to continue interacting with the same individual or outgroup in a subsequent task. The results for this variable mirrored those for trusting behavior, and hence are not reported here.

${ }^{2}$ Here too, the main effects of Interaction Type $(F(1$, $264)=19.50, p<0.001, f=0.27)$ and Apology Type $(F(2,264)=35.82, p<0.001, f=0.52)$ were significant, as was the interaction effect between Interaction Type and Apology Type, $F(2,264)=5.28, p=0.006, f=0.20$.

${ }^{3}$ Some previous research indicates that gender can play a relevant role in trust and conflict resolution strategies and may moderate differences between interpersonal and intergroup interactions (e.g., Schopler et al., 2001). To explore this possibility, we also conducted the main analysis of self-reported trust with gender included as an additional factor. The results revealed an interaction effect between trust trajectory, interaction type, and gender, $F(1.97$, $519.66)=12.47, p<0.001$. This finding indicated that male and female participants did differ in initial trust in intergroup interactions (T1, lower among male participants, $F[1,264]=7.70, p=0.006)$. Moreover, it indicated that among female participants, trust at the end of the interaction (T3) was greater in interpersonal interactions than in intergroup interactions $(F[1,264]=17.88, p<0.001)$, whereas this difference did not reach significance among male participants $(F[1,264]=1.19, p=0.28)$. Importantly, however, gender did not interact with apology, nor did its inclusion alter the significance of the interaction between interaction type and apology type on overall trust. In sum, although there were some indications that gender may influence trust and its recovery in interpersonal or intergroup contexts, there were no indications that gender may moderate the impact of an apology in these settings.

\section{Competing Interests}

The authors have no competing interests to declare.

\section{Author Contributions}

CRF and PVL developed the study concept. CRF and JDk designed the study. JDk collected the data. CRF and TH conducted the analyses. CRF wrote the manuscript in conjunction with TW; TH, JDk, JVA, and PVL provided critical input. All authors contributed to the revisions of the manuscript during the review process.

\section{References}

Berg, J., Dickhaut, J., \& McCabe, K. (1995). Trust, reciprocity, and social history. Games and Economic Behavior, 10, 122-142. DOI: https://doi. org/10.1006/game.1995.1027

Billiet, J., Maddens, B., \& Frognier, A. P. (2006). Does Belgium (still) exist? Differences in political culture between Flemings and Walloons. West 
European Politics, 29, 912-932. DOI: https://doi. org/10.1080/01402380600968802

De Visscher, C., \& Laborderie, V. (2013). Belgique: Stop ou encore? Entre fédéralisme, confédéralisme et séparatisme. Politique Étrangère, 4, 23-35. DOI: https://doi.org/10.3917/pe.134.0023

Desmet, P. T., De Cremer, D., \& van Dijk, E. (2011). Trust recovery following voluntary or forced financial compensations in the trust game: The role of trait forgiveness. Personality and Individual Differences, 51, 267-273. DOI: https://doi.org/10.1016/j. paid.2010.05.027

Dhami, M. K. (2012). Offer and acceptance of apology in victim-offender mediation. Critical Criminology, 20, 45-60. DOI: https://doi.org/10.1007/ s10612-011-9149-5

Faul, F., Erdfelder, E., Lang, A.-G., \& Buchner, A. (2007). G*Power 3: A flexible statistical power analysis program for the social, behavioral, and biomedical sciences. Behavior Research Methods, 39, 175-191. DOI: https://doi.org/10.3758/BF03193146

Fehr, R., Gelfand, M. J., \& Nag, M. (2010). The road to forgiveness: a meta-analytic synthesis of its situational and dispositional correlates. Psychological Bulletin, 136, 894-914. DOI: https://doi.org/10.1037/ a0019993

Haesevoets, T., Reinders Folmer, C. P., De Cremer, D., \& Van Hiel, A. (2013). Money isn't all that matters: The use of financial compensation and apologies to preserve relationships in the aftermath of distributive harm. Journal of Economic Psychology, 35, 95-107. DOI: https://doi.org/10.1016/j.joep.2013.02.003

Hareli, S., \& Eisikovits, Z. (2006). The role of communicating social emotions accompanying apologies in forgiveness. Motivation and Emotion, 30, 189-197. DOI: https://doi.org/10.1007/s11031-006-9025-x

Haslam, N., \& Loughnan, S. (2014). Dehumanization and infrahumanization. Annual Review of Psychology, 65, 399-423. DOI: https://doi.org/10.1146/ annurev-psych-010213-115045

Hayes, A. F. (2013). Introduction to Mediation, Moderation, and Conditional Process Analysis. A Regression-Based Approach. New York, NY: Guilford Press.

Hornsey, M. J., Okimoto, T. G., \& Wenzel, M. (2017). The appraisal gap: Why victim and transgressor groups disagree on the need for a collective apology. European Journal of Social Psychology, 47, 135-147. DOI: https://doi.org/10.1002/ejsp.2279

Hornsey, M. J., \& Wohl, M. J. (2013). We are sorry: Intergroup apologies and their tenuous link with intergroup forgiveness. European Review of Social Psychology, 24, 1-31. DOI: https://doi.org/10.1080 /10463283.2013.822206

Insko, C. A., \& Schopler, J. (1998). Differential distrust of groups and individuals. In C. Sedikides, J. Schopler \& C. A. Insko (Eds.), Intergroup Cognition and Intergroup Behavior (pp. 75-107). Mahwah, NJ: Lawrence Erlbaum Associates.

Insko, C. A., Schopler, J., Gaertner, L., Wildschut, T., Kozar, R., Pinter, B., Finkel, E. J., Brazil, D. M.,
Cecil, C. L., \& Montoya, M. R. (2001). Interindividual-intergroup discontinuity reduction through the anticipation of future interaction. Journal of Personality and Social Psychology, 80, 95-111. DOI: https://doi.org/10.1037/0022-3514.80.1.95

Lerner, M. J. (1991). Integrating societal and psychological rules of entitlement. In: R. Vermunt \& H. Steensma (Eds), Social Justice in Human Relations (Vol. 1, pp. 13-32). New York: Plenum Press.

Leunissen, J. M., De Cremer, D., Reinders Folmer, C. P., \& Van Dijke, M. (2013). The apology mismatch: Asymmetries between victim's need for apologies and perpetrator's willingness to apologize. Journal of Experimental Social Psychology, 49, 315-324. DOI: https://doi.org/10.1016/j.jesp.2012.12.005

Leyens, J. P., Paladino, P. M., Rodriguez-Torres, R., Vaes, J., Demoulin, S., Rodriguez-Perez, A., \& Gaunt, R. (2000). The emotional side of prejudice: The attribution of secondary emotions to ingroups and outgroups. Personality and Social Psychology Review, 4, 186-197. DOI: https://doi.org/10.1207/ S15327957PSPR0402_06

Okimoto, T. G., \& Tyler, T. R. (2007). Is compensation enough? Relational concerns in responding to unintended inequity. Group Processes \& Intergroup Relations, 10, 399-420. DOI: https://doi. org/10.1177/1368430207078701

Pemberton, M. B., Insko, C. A., \& Schopler, J. (1996). Memory for and experience of differential competitive behavior of individuals and groups. Journal of Personality and Social Psychology, 71, 953-966. DOI: https://doi.org/10.1037/0022-3514.71.5.953

Philpot, C. R., \& Hornsey, M. J. (2008). What happens when groups say sorry: The effect of intergroup apologies on their recipients. Personality and Social Psychology Bulletin, 34, 474-487. DOI: https://doi. org/10.1177/0146167207311283

Pinter, B., Insko, C. A., Wildschut, T., Kirchner, J. L., Montoya, R. M., \& Wolf, S. T. (2007). Reduction of interindividual-intergroup discontinuity: The role of leader accountability and proneness to guilt. Journal of Personality and Social Psychology, 93, 250-265. DOI: https://doi. org/10.1037/0022-3514.93.2.250

Reinders Folmer, C. P., Klapwijk, A., De Cremer, D., \& van Lange, P. A. M. (2012). One for all: What representing a group may do to us. Journal of Experimental Social Psychology, 48, 1047-1056. DOI: https:// doi.org/10.1016/j.jesp.2012.04.009

Reinders Folmer, C. P., Wildschut, T., De Cremer, D., \& van Lange, P. A. M. (2019). Coping with noise in social dilemmas: Group representatives fare worse than individuals because they lack trust in others' benign intentions. Group Processes \& Intergroup Relations, 22, 200-214. DOI: https://doi. org/10.1177/1368430217722036

Reuchamps, M., Boerjan, H., Niessen, C., \& Randour, F. (2021). More or less regional autonomy? A qualitative analysis of citizen arguments towards (de) centralization in Belgium. Comparative European 
Politics, 1-23. DOI: https://doi.org/10.1057/ s41295-020-00234-1

Rimé, B., Bouchat, P., Klein, O., \& Licata, L. (2015). When collective memories of victimhood fade: Generational evolution of intergroup attitudes and political aspirations in Belgium. European Journal of Social Psychology, 45, 515-532. DOI: https://doi. org/10.1002/ejsp.2104

Rychlowska, M., Van Der Schalk, J., Gratch, J., Breitinger, E., \& Manstead, A. S. (2019). Beyond actions: Reparatory effects of regret in intergroup trust games. Journal of Experimental Social Psychology, 82, 74-84. DOI: https://doi.org/10.1016/j. jesp.2019.01.006

Schopler, J., Insko, C. A., Drigotas, S. M., Wieselquist, J., Pemberton, M., \& Cox, C. (1995). The role of identifiability in the reduction of interindividualintergroup discontinuity. Journal of Experimental Social Psychology, 31, 553-574. DOI: https://doi. org/10.1006/jesp.1995.1025

Schopler, J., Insko, C. A., Wieselquist, J., Pemberton, M. B., Witcher, B., Kozar, R., ... Wildschut, T. (2001). When groups are more competitive than individuals: The domain of the discontinuity effect. Journal of Personality and Social Psychology, 80, 632-644. DOI: https://doi.org/10.1037/0022-3514.80.4.632

Schumann, K. (2014). An affirmed self and a better apology: The effect of self-affirmation on transgressors' responses to victims. Journal of Experimental Social Psychology, 54, 89-96. DOI: https://doi. org/10.1016/j.jesp.2014.04.013

Shnabel, N., \& Nadler, A. (2015). The role of agency and morality in reconciliation processes: The perspective of the needs-based model. Current Directions in Psychological Science, 24, 477-483. DOI: https://doi. org/10.1177/0963721415601625

Shnabel, N., Nadler, A., Ullrich, J., Dovidio, J. F., \& Carmi, D. (2009). Promoting reconciliation through the satisfaction of the emotional needs of victimized and perpetrating group members: The needs-based model of reconciliation. Personality and Social Psychology Bulletin, 35, 1021-1030. DOI: https://doi. org/10.1177/0146167209336610

Shore, D. M., Rychlowska, M., van der Schalk, J., Parkinson, B., \& Manstead, A. S. (2019). Intergroup emotional exchange: Ingroup guilt and outgroup anger increase resource allocation in trust games. Emotion, 19, 605. DOI: https://doi. org/10.1037/emo0000463

Slocum, D., Allan, A., \& Allan, M. M. (2011). An emerging theory of apology. Australian Journal of Psychology, 63, 83-92. DOI: https://doi. org/10.1111/j.1742-9536.2011.00013.x

Tavuchis, N. (1991). Mea Culpa: A Sociology of Apology and Reconciliation. Stanford: Stanford University Press.

Van Assche, J., Bostyn, D., De keersmaecker, J., Dardenne, B., \& Hansenne, M. (2017). Intergroup reconciliation between Flemings and Walloons: The predictive value of cognitive style, authoritarian ideology, and intergroup emotions. Psychologica Belgica, 57, 132-155. DOI: https://doi.org/10.5334/ pb.333

Verhaegen, S., Dupuy, C., \& Van Ingelgom, V. (2021). Experiencing and supporting institutional regionalization in Belgium: A normative and interpretive policy feedback perspective. Comparative European Politics, 1-28. DOI: https://doi.org/10.1057/ s41295-020-00235-0

Wenzel, M. (2004). A social categorisation approach to distributive justice. In: W. Stroebe \& M. Hewstone (Eds), European Review of Social Psychology (Vol. 15, pp. 219-257). Hove: Psychology Press. DOI: https:// doi.org/10.1080/10463280440000035

Wenzel, M., Lawrence-Wood, E., Okimoto, T. G., \& Hornsey, M. J. (2018). A long time coming: Delays in collective apologies and their effects on sincerity and forgiveness. Political Psychology, 39, 649-666. DOI: https://doi.org/10.1111/pops.12421

Wildschut, T., \& Insko, C. A. (2006). A paradox of individual and group morality: Social psychology as empirical philosophy. In P. A. M. van Lange (Ed.), Bridging Social Psychology: The Benefits of Transdisciplinary Approaches (pp. 377-384). Hillsdale, NJ: Erlbaum.

Wildschut, T., \& Insko, C. A. (2007). Explanations of interindividual-intergroup discontinuity: A review of the evidence. European Review of Social Psychology, 18, 175-211. DOI: https://doi. org/10.1080/10463280701676543

Wildschut, T., Insko, C. A., \& Gaertner, L. (2002). Intergroup social influence and intergroup competition. Journal of Personality and Social Psychology, 82, 975-992. DOI: https://doi. org/10.1037/0022-3514.82.6.975

Wildschut, T., Insko, C. A., \& Pinter, B. (2004). The perception of outgroup threat: Content and activation of the outgroup schema. In V. Yzerbyt, C. M. Judd, \& O. Corneille (Eds.), The Psychology of Group Perception (pp. 335-359). Philadelphia, PA: Psychology Press.

Wildschut, T., Insko, C. A., \& Pinter, B. (2007). Interindividual-intergroup discontinuity as a joint function of acting as a group and interacting with a group. European Journal of Social Psychology, 37, 390-399. DOI: https://doi.org/10.1002/ejsp.374

Wildschut, T., Pinter, B., Vevea, J. L., Insko, C. A., \& Schopler, J. (2003). Beyond the group mind: A quantitative review of the interindividual-intergroup discontinuity effect. Psychological Bulletin, 129, 698-722. DOI: https://doi. org/10.1037/0033-2909.129.5.698

Wohl, M. J., Hornsey, M. J., \& Bennett, S. H. (2012). Why group apologies succeed and fail: Intergroup forgiveness and the role of primary and secondary emotions. Journal of Personality and Social Psychology, 102, 306-322. DOI: https://doi.org/10.1037/ a0024838 
How to cite this article: Reinders Folmer, C. P., Wildschut, T., Haesevoets, T., De keersmaecker, J., Van Assche, J., \& Van Lange P. A. M. (2021). Repairing Trust Between Individuals and Groups: The Effectiveness of Apologies in Interpersonal and Intergroup Contexts. International Review of Social Psychology, 34(1): 14, 1-15. DOI: https://doi.org/10.5334/irsp.479

Submitted: 20 June 2020 Accepted: 25 May 2021 Published: 02 July 2021

Copyright: (c) 2021 The Author(s). This is an open-access article distributed under the terms of the Creative Commons Attribution 4.0 International License (CC-BY 4.0), which permits unrestricted use, distribution, and reproduction in any medium, provided the original author and source are credited. See http://creativecommons.org/licenses/by/4.0/.

] International Review of Social Psychology is a peer-reviewed open access journal published 